\title{
EJWI Vol. 1, No. 1
}

Hans Christian Garmann Johnsen 
Workplace innovation has developed as a topic over many years, and is connected to different historical and theoretical discussions. Political and ideological conditions have, to various extents, been favourable to this development. The issue is also how to define workplace innovation in relation to other initiatives and perspectives on innovation. One might also ask if this is a typical European phenomenon, or whether it requires a certain perspective on politics in general. The contributions to this issue of EJWI have in common that they try to define what workplace innovation is and should be, and link it to the history of workplace development and the workplace development discourse.

Starting from the work of F. Taylor, Dhondt argues for a workplace innovation concept that is broad, in the sense that it goes beyond micro sociological processes at the workplace. It is rather a concept that asks for a renewal of the understanding of work and workplaces. New business models, if you like. This new model should take a broader set of objectives into account, inequality, integration of organisation and environment and acknowledgement of the intangible aspects of business. It should create a new dialogue between organisational economics, organisational sociology and organisational psychology. It should go beyond business concepts such as dynamic capabilities or organisational capital. It should take a new look at the sociotechnical tradition.

Gustavsen takes the history of workplace development programmes in Scandinavia as a point of departure. He argues that democratic dialogue is needed in order to address the current challenges in work life. His argument is that dialogue is something beyond business model and concepts. It is a reflective capacity to see and integrate a wide set of experiences. In fact, the Scandinavian models which are seen as rather successful in promotion and leading innovation did not appear by design. They gradually developed because of the conditions for dialogue. Gustavsen further argues that conditions for dialogue at the workplace are better today than ever, because of the relative peacefulness in work life. Only this dialogue will be able to combat non-dialogical forms of communication. It is through dialogue that the real, underlying issues that are important for people can come to the surface. This again is argued as an alternative to grand theory: workplace development can only happen if real, reflective and open dialogue is possible.

Alasoini discusses the Finnish experience of promoting workplace development, and sees it in a European perspective. He argues that there are contradictory aspects of this development. On the one hand, Finland was slower in adopting work organisation development as a key priority. However, in the 1990s and 2000, it has come to the forefront of politics, and has after this been promoted through continuous government programmes. On the other hand, he argues that these programmes, although they have had good intentions, have not had the expected effect. One can learn from these programmes that it is possible to promote a broad perspective on workplace innovation. These programmes have taken a system approach, argued for both work quality and productivity, promoted local learning, been based on co-operation between social partners, been supported by research, and linked to welfare objectives. However, the experience shows that it is difficult to succeed with this broad agenda. Alasoini's argument is not to give up the ambitions of these programmes, which seem even more relevant in the future of work life, but to learn more about how to make their ideas become useful in practice.

Totterdill makes a similar argument to the others, but argues in a different way. He uses the Fifth Element as an organising principle in his reflections. The point of departure is that there is a gap between what we know (in terms of workplace innovation research) and what we practice (in terms of what businesses report as their practice). In short, businesses are more hierarchical, management driven, less inclusive, make less use of employees' knowledge, create 
less autonomous workplaces, than what work life research recommends. The reason for this is that managers do not see their challenges in a comprehensive way. Rather work design, quality of work, productivity, innovation, etc., are seen as separate things. The Fifth Element is thus a concept that argues for the need to create a dialogue at the workplace where managers, employees and researchers meet.

The four articles have in common that they argue for a very broad concept of workplace innovation, one that is able to communicate with a renewed thinking on business models and work at a societal level. They promote procedures rather than solutions and fixed models. They all seem to acknowledge that the challenges of work life are diverse and complex, and that we cannot diagnose future development. However, we can establish structures and procedures for co-operation, dialogue and openness to change, that will support innovation and democratic development. 
